\title{
Assessment of Renal Function among HIV-Infected Patients on Combination Antiretroviral Therapy at Tikur Anbessa Specialized Hospital, Addis Ababa, Ethiopia
}

\author{
Kassahun Eneyew ${ }^{1}$, Daniel Seifu ${ }^{2}$, Wondwossen Amogne ${ }^{3}$, M. K. C. Menon ${ }^{2}$ \\ ${ }^{1}$ Department of Biochemistry, College of Health Sciences, Hawassa University, Hawassa, Ethiopia \\ ${ }^{2}$ Department of Medical Biochemistry, School of Medicine, Faculty of Health Sciences, Addis Ababa University, \\ Addis Ababa, Ethiopia \\ ${ }^{3}$ Department of Internal Medicine, School of Medicine, Faculty of Health Sciences, Addis Ababa University, \\ Addis Ababa, Ethiopia \\ Email: *eneyewk@yahoo.com
}

Received 17 June 2016; accepted 16 August 2016; published 19 August 2016

Copyright (C 2016 by authors and Scientific Research Publishing Inc.

This work is licensed under the Creative Commons Attribution International License (CC BY). http://creativecommons.org/licenses/by/4.0/

(c) (i) Open Access

\begin{abstract}
Background: Acquired immunodeficiency syndrome (AIDS) is a spectrum of disease states characterized by progressive immunosuppression. Sub-Saharan Africa is heavily affected by human immunodeficiency virus (HIV) and AIDS than any other region of the world. Renal complications are important component of advanced HIV disease, and these complications significantly contribute to morbidity and mortality in HIV/AIDS patients. Aim of the Study: To assess renal function abnormalities in HIV infected patients and compare with treatment-naive and HIV-negative control groups. Methods: A retrospective cross sectional study of comparative nature was designed and samples and biochemical data were collected from July 1/2012 to February $1 / 2013$ in patients attending the ART clinic at Tikur Anbessa Specialized Hospital, Addis Ababa, Ethiopia. Renal functions of 180 participants were assessed. The data obtained were analyzed using SPSS version 16.0. Result: A total of 180 participants grouped as HIV-negative controls $(n=60)$, HIV+ treatmentnaive $(n=60)$ and HIV+ on HAART were recruited to participate in this study. Out of 180 participants included in the study, $59(32.78 \%)$ were males and the remaining $121(67.22 \%)$ were females. Mean serum total protein was higher in patients on HAART groups $(5.78 \pm 1.39)$ than treatment-naive $(4.76 \pm 2.19)$. There was significant reduction $(p<0.05)$ in serum total protein in
\end{abstract}

*Corresponding author.

How to cite this paper: Eneyew, K., Seifu, D., Amogne, W. and Menon, M.K.C. (2016) Assessment of Renal Function among HIV-Infected Patients on Combination Antiretroviral Therapy at Tikur Anbessa Specialized Hospital, Addis Ababa, Ethiopia. Technology and Investment, 7, 107-122. http://dx.doi.org/10.4236/ti.2016.73013 
both HIV+ groups as compared with the control groups. The mean serum creatinine level was not significantly different among three groups. The mean serum creatinine clearance in treatmentnaive groups $(111.05 \pm 11.33)$ was lower than the control groups $(115.05 \pm 44.41)$ and patients on HAART (114.76 \pm 28.54$)$. There was a positive and significant correlation of glomerular filtration rate with BMI on treatment-naive groups. Conclusion: There are no statistically significant differences in the levels of Creatinine clearance and Estimated Glomerular Filtration Rate (eGFR) in HIV positive patients (naive as well as treated) as compared to the negative controls. The prevalence of renal impairment as defined by $\mathrm{CrCl}<60 \mathrm{~mL} / \mathrm{min}$ (eGFR $<60 \mathrm{ml} / \mathrm{min} / 1.73 \mathrm{~m}^{2}$ ) is higher in treatment-naive participants than those on HAART and HIV-negative control groups.

\section{Keywords}

Renal Dysfunction, HAART, HIV-Infected Patients, eGFR, Creatinine Clearence, HIVAN

\section{Introduction}

According to the World Health Organization, since human immunodeficiency virus (HIV) and acquired immunodeficiency syndrome (AIDS) were first described, HIV-AIDS is estimated to have killed more than 25 million people worldwide [1]. There are approximately 34 million people currently living with HIV and about 30 million people have died of AIDS-related causes since the beginning of the epidemic [2]. Despite evidence that prevention programs are beginning to have an impact in some countries, the HIV-AIDS epidemic continues to grow, and by 2005 the number of people infected worldwide grew to more than 40 million [3]. Therefore, HIV-AIDS continues to pose a significant threat to global health and a challenge to the medical profession. Sub-Saharan Africa is more heavily affected by HIV and AIDS than any other region of the world. An estimated 22.9 million people are living with HIV in the region-around two thirds of the global total [4]. Since the first case of HIV reported in Ethiopia in 1984, HIV/AIDS has become a major public health concern and development challenge for Ethiopia with high population growth rate, poverty, food shortages, low access to clean water and sanitation and quality health services, and other socioeconomic factors continue to fuel the epidemic [5]. According to the data from the 2011 Ethiopian demographic health survey adult HIV/AIDS prevalence in Ethiopia was estimated to be $1.5 \%$ and approximately 1.2 million Ethiopians were living with HIV/AIDS. The prevalence was higher among women (1.9\%) than men (1.0\%) [5] [6].

The attenuation of HIV scourge has been partly ascribed to treatment with highly active antiretroviral therapy (HAART) and better care for people living with the pandemic. However, with increased life expectancy of the affected individuals due to drug therapy, kidney diseases have emerged as the possible cause of morbidity and mortality [7]. Infection with HIV has been associated with many types of renal diseases including acute renal failure, acute tubular necrosis, and HIV-associated nephropathy (HIVAN) which ultimately may progress to end stage renal disease (ESRD) [8] [9], within few months if left untreated. Studies have shown that the prevalence of HIV associated renal disease varies according to geographical locations [10] [11] and race with estimated 14\% of black patients and 6\% of white patients who died from HIV infection in the United States in 1999 having renal disease [12]. In Iran, for example, the HIV infected patients had no electrolyte imbalance, proteinuria or renal failure [13]. However, with regard to Nigerians infected with HIV, azotaemia has been used as a good marker of HIV nephropathy [14]. In addition to HIV infections, black race, older age, HAART use, hypertension, diabetes, low CD4+ cell count, and high viral load remained important risk factors for kidney disease [15]-[21]. Every system in the human body may be affected by HIV-AIDS, and imaging plays a pivotal role in demonstrating the complex disease processes that result from HIV infection. Lipid profile derangements after receiving first-line ART in HIV-patients, has also been reported in a Ethiopian hospital [22]. Neurologic, respiratory, and gastrointestinal complications have all been extensively described in the medical literature; however, renal manifestations and, in particular, their imaging characteristics, are less described. The introduction of HAART also known as combination antiretroviral therapy (cART) in 1996 has revolutionized the management of HIV infection. In patients for whom HAART is available, this therapy has been shown not only to reduce mortality and morbidity rates, but also to improve the quality of life and to delay or even prevent the progression to AIDS in many cases. 
Some antiretroviral agents (e.g. nucleotide reverse-transcriptase inhibitors such as tenofovir, protease inhibitors such as indinavir) can cause serious side effects that affect multiple systems, including the kidneys [23]. Tenofovir (tenofovir disoproxil fumarate) has been associated with development of acute renal failure (ARF) and dysfunction of proximal and distal tubules. Verhelst et al. (2002) [24] first described a patient who was treated with tenofovir and developed reversible Fanconi syndrome, nephrogenic diabetes insipidus and ARF. Renal biopsy demonstrated cytoplasmic vacuolization, apical localization of nuclei, and reduction of the brush border on proximal tubule epithelial cells. Tenofovir is taken up into renal epithelial cells by basolateral membrane human organic anion transporters, then secreted into the urine across the apical membrane by transporters called multidrug-resistance-associated proteins [25]. Other transporters may also be involved. A study showed a better outcome with efavirenz (EFV)-based ART compared with nevirapine (NVP) [26]. Concomitant use of ritonavir (alone or in combination with lopinavir or other PI raises plasma concentrations of tenofovir and may increase the risk for renal dysfunction as a result of inhibition by ritonavir of apical membrane transporters and increased intracellular accumulation of tenofovir. The actual mechanism of toxicity remains to be determined. However, Microalbuminuria, as a marker in assessing kidney disease risk in Brazilian hospitals, has been evaluated after ART in HIV-patients [27].

Indinavir has been associated with Crystalluria, nephrolithiasis, and obstructive ARF [12] [28]-[30]. Asymptomatic Crystalluria occurs in up to two thirds of treated patients; pyuria, microscopic hematuria, and low-grade proteinuria are also seen. Indinavir Crystalluria and nephrolithiasis can present with back or flank pain, dysuria, urinary urgency, and gross hematuria. Indinavir is metabolized primarily in the liver, but renal excretion of parent drug accounts for approximately $10 \%$ of a dose. Indinavir is highly soluble in acidic urine but relatively insoluble in more alkaline urine, predisposing to the development of crystals at typical urine $\mathrm{pH}$ levels [31]. Crystals of varying shapes have been described and are more common in urine with $\mathrm{pH} 6$ [29] [30] [32]. Urinary stones are composed primarily of indinavir monohydrate; calcium oxalate and phosphate as well as indinavir metabolites may also be present [29] [33].

Chronic kidney disease that may progress to end-stage renal disease requiring dialysis and renal transplant can be diagnosed in its earlier stage through routine screening and careful attention to changes in renal functions [34]. In economically disadvantaged settings of developing countries, where renal transplant and dialysis may not be accessible, early detection of renal disease may have some clinical and financial implications for people living with HIV/AIDS.

HIV infection can cause a broad spectrum of clinical manifestations, ranging from an asymptomatic carrier state to severe immunodeficiency. Patients infected with HIV have been described to have an unusual form of renal disease known as HIV-associated nephropathy. This condition is characterized by nephritic range proteinuria, rapid progression to renal insufficiency and a morphologic pattern of focal segmental glomerulosclerosis (FSGS) on renal biopsies [35]. Problems with kidney function in HIV infected people may be due to medications or HIV itself. HIVAN is now being recognized as a distinct clinico-pathological entity that presents with proteinuria in the nephrotic range and impairment of renal function. Many antiretroviral agents are eliminated at least partly by the kidneys and require dosage adjustments in patients with reduced glomerular filtration rate (GFR). Although, the infectious disease society of America (IDSA) HIV renal guidelines [36] recommends determination of baseline renal function prior to initiation of antiretroviral (ARVs) therapy, many programs in sub-Saharan Africa initiate treatment without this assessment, due to resource constraints [37]. Renal failure was defined as an increase in serum creatinine level more than $30 \%$ of basal level, or blood urea nitrogen $>20 \mathrm{mg} / \mathrm{dL}$ and serum creatinine level $>1.3$ (in females) or $>1.5 \mathrm{mg} / \mathrm{dL}$ (in males). The present study was undertaken, because of the increasing prevalence of HIV and the growing demands for HAART, and failure of determination of renal function prior to initiation of antiretroviral therapy. This study was also conducted, with the aim to assess the impact of HIV infection, with or without HAART on renal functions of HIV infected individuals, receiving treatment at ART clinic in Tikur Anbessa Specialized Hospital, Addis Ababa, Ethiopia.

\section{Methods}

\subsection{Study Design and Study Period}

The study design was a cross-sectional study in patients attending the ART clinic at Tikur Anbessa Specialized Hospital, Addis Ababa, Ethiopia. The Tikur Anebassa is a 700-bed hospital with 110 medical beds. It is a tertiary referral centre for the whole of Ethiopia and has 2 nephrologists. 


\subsection{Study Area and Study Population}

Patients were identified from the ART/HIV Clinic at Tikur Anbessa Specialized Hospital, Addis Ababa, Ethiopia. HIV-infected individuals seen for routine clinical visits were enrolled in the current study. There are around 5015 adult patients in ART/HIV Clinic at Tikur Anbessa Specialized Hospital in 2012/13. Of these 2281 were in the first line, 133 were in the second line and 2465 are HIV-naive patients. First line regimens that patients were taking included $4 \mathrm{a}=\mathrm{d} 4 \mathrm{~T} / 3 \mathrm{Tc} / \mathrm{NVP}$ (Stavudine, Lamivudine, Nevirapine), $4 \mathrm{~b}=\mathrm{d} 4 \mathrm{~T} / 3 \mathrm{Tc} / \mathrm{EFV}$ (Stavudine, Lamivudine, Efavirenz), 4c = AZT/3Tc/NVP (Zidovudine, Lamivudine, Nevirapine), and 4d = AZT/ 3Tc/EFV (Zidovudine, Lamivudine, Efavirenz). Some patients were also on the following second line regimens: $\mathrm{ABC} / \mathrm{ddi} / \mathrm{LPv} / \mathrm{r}$ (Abacavir, Didanosine, ritonavir, enhanced Lopinavir), AZT/3Tc/LPv/r (Zidovudine, Lamivudine, Ritonavir, enhanced Lopinavir) and D4T/3TC/LPv/r (Stavudine, Lamivudine, retonavir enhanced Lopinavir). Records from the ART clinic were reviewed to identify patients who meet clinical and laboratory criteria for entry and these patients were sequentially offered entry into this study. Blood samples were obtained from ART-naive patients and from those who are already on ART treatment. In addition, HIV-negative individuals (control groups) were enrolled.

\subsection{Study Variables}

\subsubsection{Dependant Variable}

Total protein, urea, uric acid, creatinine, creatinine clearance and glomerular filtration rate in all three groups.

\subsubsection{Independent Variable}

Duration of HAART intake; Life style and Race.

\subsubsection{Sample Size}

Assuming an average of $11.5 \%$ prevalence rate of renal insufficiency among ART naive patients, at 5\% precision and 95\% level of confidence interval, the sample size calculated using the formula shown below is 156 .

Using the formula

$$
\mathrm{N}=\mathrm{Z}^{2} \mathrm{P}(1-\mathrm{p}) / \alpha^{2}
$$

where $\mathrm{N}=$ sample size

$\mathrm{Z}=1.96$ Critical value at $95 \%$ level of confidence

$\mathrm{p}=$ Proportion of renal insufficiency

$\alpha=$ type-I error (0.05)

Among the three arms of the study, these numbers were equally split; hence 60 patients were recruited at each arm. Quota sampling were employed i.e. all patients who fulfill the inclusion criteria and consenting for the study were recruited consecutively.

\subsubsection{The Inclusion Criteria}

HIV infected patients' naive to combination antiretroviral therapy (cART); HIV infected patients on cART for at least 3 months; HIV-negative participants seen at the clinic of Tikur Anbessa Specialized Hospital were included in the study.

\subsubsection{The Exclusion Criteria}

Patients known to have acute or chronic kidney disease; taking nephrotoxic drugs; or pregnant; or known to have diabetes mellitus, known to be hypertensive; HBsAg + ve; HCV Ab +ve; were excluded from the study.

\subsubsection{Ethical Consideration}

After being approved by the Research and Ethical Committee of the Department of Biochemistry, School of Medicine, College of Health science, Addis Ababa University, with protocol number 0013/2012, formal letters were written to Tikur Anbessa Specialized Hospital, Ethiopia. In addition, the whole aim of the study was briefly explained to all concerned authorities as well as to the technical staff who were assigned in the ART unit so as to get permission and support. Participants who consented to give blood were recruited in the study. Moreover, confidentiality was strictly maintained throughout the course of the study and the study outcomes were brought 
to the notice of the Biochemistry Department, Addis Ababa University as well as to the hospital authorities.

\subsubsection{Clinical and Anthropometric Measurements}

Clinical and Anthropometric measurements regarding each participant's sex, age, height, pulse blood pressure, and parameters of special interest such as; known duration of HIV infection (time since diagnosis of HIV), medical records of kidney disease and factors known to contribute to kidney disease, known systemic complications, as well as, treatment regimen status were collected using a standardized questionnaire or data sheet format. Patients with a prior diagnosis of diabetes mellitus, hypertension, acute or chronic kidney disease, taking nephrotoxic drugs, pregnant women and patients with hepatitis B, C were excluded from the study.

\subsubsection{Weight and Height, Body Mass Index, Blood Pressure Measurement}

Analog scale with kg reading was used to measure the weight of study subjects. Height was also measured while they were standing erect there by lowering the horizontal scale bar snugly to the crown of the head.

Body mass index (BMI): BMI = weight $(\mathrm{kg}) /$ height squared $\left(\mathrm{m}^{2}\right)$.

Blood pressure of the subjects was measured according to the WHO recommendation using a sphygmomanometer. Both systolic and diastolic blood pressure measurements were taken in units of millimeter mercury (mmHg).

\subsubsection{Blood Sample Collection and Handling}

Non fasting venous bloods $(5.0 \mathrm{~mL})$ were collected by trained professionals from each participant. The blood sample were dispensed into jell coated serum separatory test tube and centrifuged at 3500 revolution per minute (rpm) for 10 minutes for the separation of the serum. Serum was frozen at $-18^{\circ} \mathrm{C}$ when analyses were not carried out immediately. Serum total protein, urea, uric acid and creatinine were estimated (using Roche/Hitachi 902 analyser, Germany). In addition, creatinine clearance and eGFR were calculated from serum creatinine, age, sex and weight of the study participants.

\subsection{Methods of Biochemical Analysis}

\subsubsection{Determination of Creatinine by Jaffe Reaction}

Creatinine forms an alkaline solution which forms an orange-red complex with picric acid. The absorbance of this complex is proportional to creatinine concentration in the sample. The absorbance of the complex is measured at $492 \mathrm{~nm}$ [38].

\subsubsection{Determination of eGFR}

Serum creatinine is routinely measured as an indicator of renal function. Because creatinine is influenced by age, gender and race, chronic kidney disease may not be detected using serum creatinine alone. Thus, the National Kidney Disease Education Program strongly recommends that laboratories routinely report an eGFR when serum creatinine is measured for patients 18 and older. Routinely reporting the eGFR with all serum creatinine determinations allows laboratories to help identify individuals with reduced kidney function and help facilitate the detection of CKD. In adults, the best equation for estimating glomerular filtration rate from serum creatinine is Modification of Diet in Renal Disease (MDRD) Study equation [39]. This MDRD study equation calculator is for use with $\mathrm{S}_{\mathrm{Cr}}$ reported in $\mathrm{mg} / \mathrm{dL}$.

Calculation: $\mathrm{GFR}=186 \times\left(\mathrm{S}_{\mathrm{Cr}}\right)^{-1.154} \times(\text { Age })^{-0.203} \times(0.742$ if female $) \times(1.212$ if African American $)$ Levey et al. (2009) [39].

Where GFR = Glomerular Filtration Rate in $\mathrm{mL} / \mathrm{min} 1.73 \mathrm{~m}^{2}$, Age is in years, $\mathrm{S}_{\mathrm{Cr}}$ is serum creatinine in $\mathrm{mg} / \mathrm{dL}$.

\subsubsection{Determination of Total Protein by Refractometry}

Refractometry is a rapid analytical method that is used to determine serum proteins when a very small volume of serum is needed. Total proteins are the major masses of the dissolved solids in blood plasma and are commonly measured by a hand held refractometer.

Drops $(50 \mu \mathrm{L})$ of serum were placed by capillary action between a cover glass and the prism. The refractometer was held so that light is refracted through the serum layer. The refracted rays caused part of the field of view to 
be light, producing a point at which there is a sharp line between light and dark. The number (total protein) at this line on the internal scale will be read in $\mathrm{g} / \mathrm{dl}$.

\subsubsection{Determination of UREA by GLDH Method}

Urea is hydrolyzed in the presence water and urease to form ammonia and carbon dioxide. The ammonia from this reaction combines with 2 oxaloglutarate and NADH the presence of glutamate dehydrogenase (GLDH) to yield glutamate and NAD. The decrease in absorbance at $340 \mathrm{~nm}$ is proportional to the urea concentration within the given time interval.

\subsubsection{Determination of Uric Acid}

In 1980 Fossati et al. describes a procedure for assaying uric acid using uricase which produces hydrogen peroxide from uric acid. The hydrogen peroxide is then reacted with a phenolic compound to produce a red colored dye which can be measured spectrophotometrically in the visible range. The procedure is more specific and the phenolic compound, 3, 5-dichloro-2-hydroxybenzene sulfonate (DHBS), increases sensitivity due to the high absorbance coefficient of the quinoneimine dye produced. This uric acid procedure is a modification of that of Fossati et al. (1980) [40].

The hydrogen peroxide formed by the action of uricase on uric acid causes oxidative coupling of DHBS and 4-aminoantipyrine, in the presence of peroxidase, forming a red colored quinoneimine dye. The intensity of the color produced is directly proportional to the concentration of uric acid in the sample, with maximum absorbance at $520 \mathrm{~nm}$.

\subsubsection{Determination of Creatinine Clearance}

Creatinine clearance can be calculated from the patient's sex, age and serum creatinine using Cockcroft and Gault formula [21] [41].

Calculation: Cockcroft and Gault normalized

Male $\mathrm{CrCl}=(140-$ age $) \times($ weight $) /(\mathrm{SCr} \times 72)$

Female $\mathrm{CrCl}=(140-$ age $) \times($ weight $) \times 0.85 /\left(\mathrm{S}_{\mathrm{Cr}} \times 72\right)$

where $\mathrm{CrCl}=$ Creatinine clearance in $\mathrm{mL} / \mathrm{min}$

Age is in years

Weight is in kilograms

$\mathrm{S}_{\mathrm{Cr}}$ is serum creatinine in $\mathrm{mg} / \mathrm{dL}$

\subsubsection{Hepatitis B, C serology Test}

Hepatitis B, C serology tests were done using Enzyme-Immuno-Assay (EIA) kits.

\subsubsection{CD4+ T Cell Count Tests}

CD4+ T cell count tests were determined by BD Fluorescence-activated cell sorting (FACS) count version 1.0 01/08 machine.

\subsection{Statistical Analysis}

Data were entered using Epi info and exported to SPSS version 16. Analyses were done using SPSS version 16. Comparison of parameters was done using one way analysis of variance (ANOVA) followed by Dunnett test and correlations between parameters were analyzed using Pearson correlation analysis. Values are expressed as mean \pm S.D./or proportion (percentage) with statistical significance set at $\mathrm{P}$ value less than $0.05(\mathrm{p}<0.05)$ were considered statistically significant.

\section{Results}

\subsection{Age, Sex, Body Mass Index, Blood Pressure and CD4+ Measurements of the Study Participants}

A total of 180 participants grouped as controls $(n=60)$, HIV-naive $(n=60)$ and HIV+ on HAART $(n=60)$ were recruited to participate in this study. All the study participants were required to voluntarily respond to the 
questionnaire, give required volume of blood and sign on the informed consent. As shown in Table 1, out of 180 participants included in the study, 59 (32.78\%) were males and the remaining 121 (67.22\%) were females. Female participants were much higher in all groups. The mean age of controls, HIV-naive and HIV+ on HAART were $39.23 \pm 13.43,38.81 \pm 8.97$ and $39.48 \pm 9.35$, respectively. Age distributions were similar in all three groups. The mean duration of HIV infection, since confirmed by laboratory tests were $51.23 \pm 41.35$ SD months ranging from 2 to 192 months. The mean duration of participants on HAART were $53.3 \pm 40.67$ ranging from 5 to 113 months. The mean body mass index in controls, HIV+ treatment-naive and HIV+ on HAART groups was $22.77 \pm 3.11,22.71 \pm 4.48$ and $22.63 \pm 3.60$, respectively. The mean systolic blood pressure in control group was $112.67 \pm 7.56 \mathrm{mmHg}$, which was similar to that of HIV+ treatment-naive and HIV+ on HAART with the respective value of $111.33 \pm 7.64$ and $111.42 \pm 8.73$. There was a reduction in CD4+ cell count in HIV patients on HAART compared with those on treatment-naive. There was lower CD4+ cell count in the HIV patients when compared with the control groups (722.43 \pm 339 ). But there was higher CD4+ cell count in HIV patients on HAART ( $379 \pm 249)$ compared with those on treatment- naive (351.7 \pm 233$)$ (Table 1$)$.

\subsection{Renal Function Tests of the Study Participants}

Serum total protein was higher in patients on HAART groups $(5.78 \pm 1.39)$ than in treatment-naive groups (4.76 \pm 2.19 ). There was significant reduction ( $<0.05$ ) in serum total protein in both HIV+ groups as compared with the control groups. There was lower serum urea in control groups $(14.00 \pm 4.45)$ than treatment-naive groups (14.23 \pm 5.68$)$ and HIV patients on HAART (14.18 \pm 4.64$)$. But serum urea is lower in patients on HAART than in those treatment-naive groups. Serum uric acid was higher in HIV subjects both on HAART $(4.79 \pm 2.20)$ and treatment-naive groups $(6.07 \pm 2.31)$ than the control groups $(4.39 \pm 1.31)$. The level of serum uric acid was higher in treatment-naive groups compared with patients on HAART. Serum creatinine level was higher in treatment-naive groups $(0.74 \pm 0.12)$ compared with those on HAART $(0.70 \pm 0.13)$ as shown in Table 2. Serum creatinine level was higher in patients on HAART groups than in control groups. There is no significant difference in serum creatinine clearance between control groups and patients on HAART. Serum creatinine clearance in treatment-naive groups is lower than those control groups and patients on HAART. The level of estimated glomerular filtration rate was comparable between the HIV patients on HAART and control groups. There was lower glomerular filtration rate in treatment-naive groups when compared with HIV patients on HAART and control groups.

\subsection{Correlation Analysis}

\subsubsection{Correlation of Body Mass Index with SBP, DBP, Age and CD4+ Cells among Treatment-Naive Groups}

According to Pearson correlation there was a positive and significant correlation of body mass index with systolic blood pressure $(r=0.28, p=0.031)$ and diastolic blood pressure $(r=0.299, p=0.020)$. But there was a positive and non significant correlation of body mass index with age $(r=0.12, \mathrm{p}=0.36)$ and CD4+ cells $(\mathrm{r}=$ $0.14, \mathrm{p}=0.28$ ) (Table 3 and Figure 1).

Table 1. Age, sex, body mass index, blood pressure and CD4+ measurements of the study participants.

\begin{tabular}{ccccc}
\hline Variables & Control & HIV+ treatment-naive & HIV+ on HAART & P-value \\
\hline Sex: n (\%) Female & $39(65)$ & $40(67.3)$ & $42(70)$ & NA \\
Male & $21(35)$ & $20(33.3)$ & $18(30)$ & NA \\
Mean Age (in years) & $39.23 \pm 13.43$ & $38.81 \pm 8.97$ & $39.48 \pm 9.35$ & 0.161 \\
Mean BMI (Kg/m²) & $22.77 \pm 3.11$ & $22.71 \pm 4.48$ & $22.63 \pm 3.60$ & 0.973 \\
Mean SBP (mmHg) & $112.67 \pm 7.56$ & $111.33 \pm 7.64$ & $111.42 \pm 8.73$ & 0.562 \\
Mean DBP (mmHg) & $73.00 \pm 6.45$ & $72.33 \pm 6.20$ & $73.83 \pm 6.40$ & 0.396 \\
Mean CD4+ (cell $/ \mu \mathrm{L})$ & $722.43 \pm 339$ & $351.7 \pm 233$ & $379 \pm 249$ & $0.001^{*}$ \\
\hline
\end{tabular}

$\mathrm{NA}=$ not available; ${ }^{*} \mathrm{p}<0.05$ were considered statistically significant; Mean BMI, SBP and DBP values are expressed as mean \pm SD; BMI = Body Mass Index, SBP = systolic blood pressure, DBP = diastolic blood pressure. 
Table 2. Renal function tests of the study participants.

\begin{tabular}{ccccc}
\hline Variables & Control & HIV + treatment-naive & HIV+ on HAART & p-value \\
\hline T.protein (g/dL) & $7.56 \pm 0.68$ & $4.76 \pm 2.19$ & $5.78 \pm 1.39$ & 0.001 \\
Urea (mg/dL) & $14.00 \pm 4.45$ & $14.23 \pm 5.68$ & $14.18 \pm 4.64$ & 0.136 \\
Uric acid (mg/dL) & $4.39 \pm 1.31$ & $6.07 \pm 2.31$ & $4.79 \pm 2.20$ & $0.001^{*}$ \\
Creatinine (mg/dL) & $0.69 \pm 0.13$ & $0.74 \pm 0.12$ & $0.70 \pm 0.13$ & 0.061 \\
CrCl (ml/min) & $115.05 \pm 44.41$ & $111.05 \pm 11.33$ & $114.76 \pm 28.54$ & 0.879 \\
GFR (ml/min/1.73/m $\left.{ }^{2}\right)$ & $132.30 \pm 27.16$ & $124.23 \pm 28.00$ & $130.80 \pm 30.73$ & 0.217 \\
\hline
\end{tabular}

Note: Values are expressed as mean $\pm \mathrm{SD} ; \mathrm{p}<0.05$ is significant when control group is compared with HIV+ groups; ${ }^{*} \mathrm{p}<0.05$ significance when control group is compared with HIV+ treatment naive.

Table 3. Correlation of body mass index with systolic BP, diastolic BP, age and CD4+ cells among treatment-naive groups.

\begin{tabular}{cccccc}
\hline & & Systolic BP & Diastolic BP & Age & CD4+ \\
\hline \multirow{2}{*}{ BMI } & $\mathrm{R}$ & 0.28 & 0.29 & 0.12 & 0.14 \\
& p-value & $0.031^{*}$ & $0.020^{*}$ & 0.36 & 0.26 \\
\hline
\end{tabular}

*Indicates significance; r-Correlation coefficient.

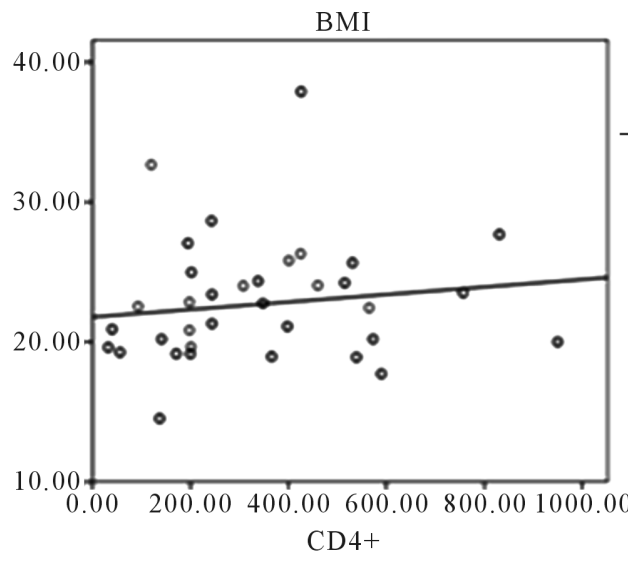

(a)

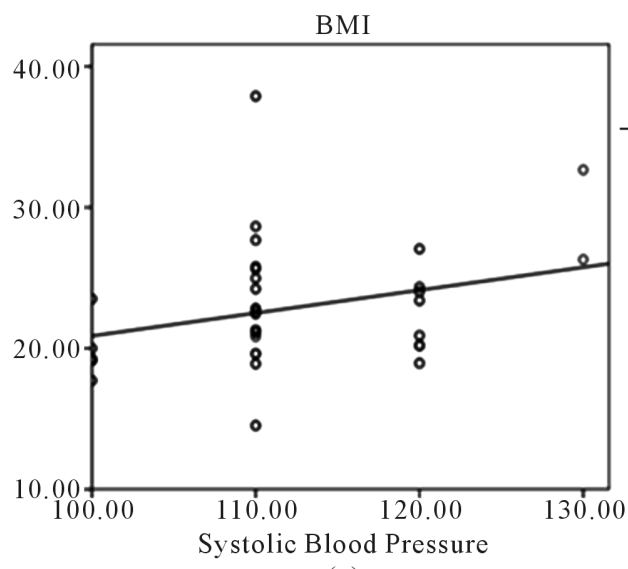

(c)

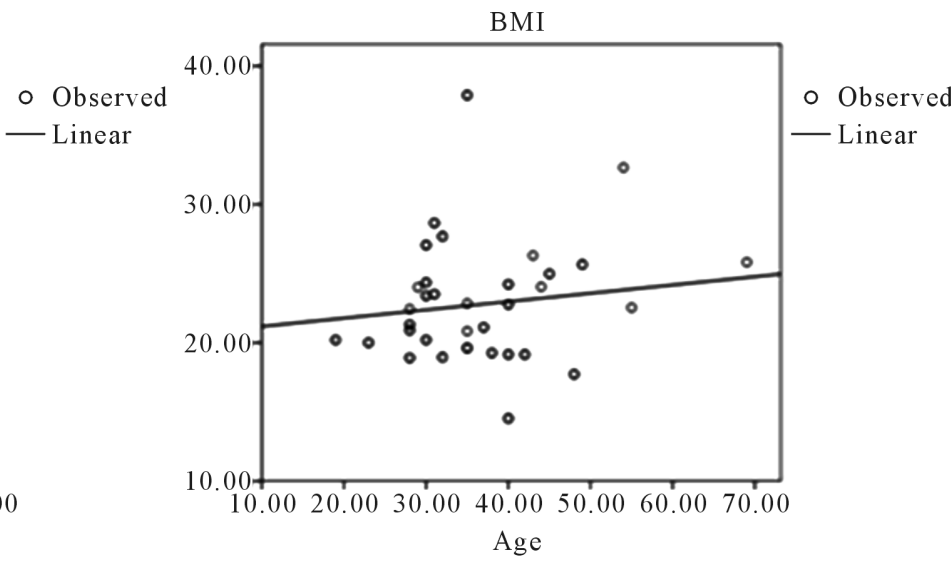

(b)

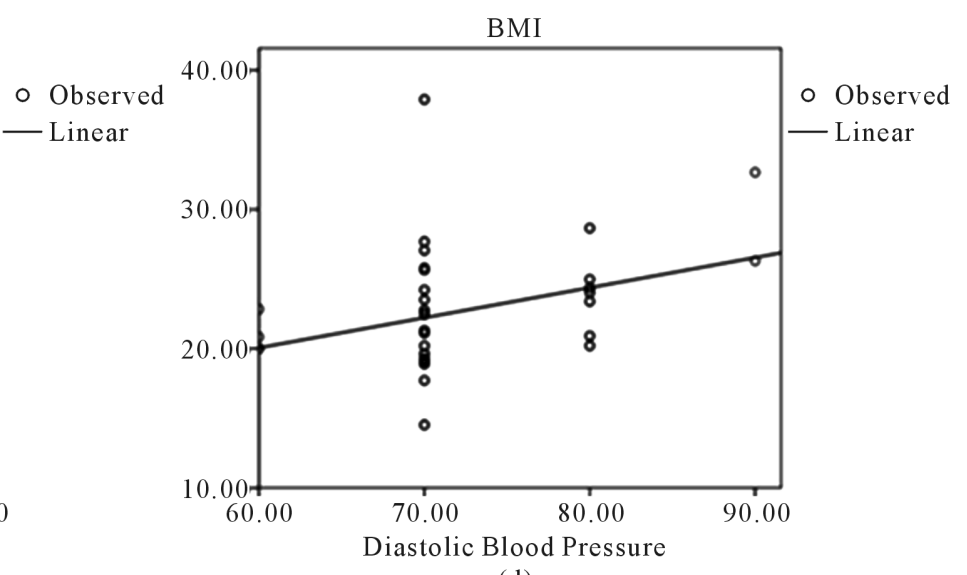

(d)

Figure 1. Correlation of: (a) BMI with CD4+ cells, (b) BMI with age, (c) BMI with systolic BP, (d) BMI with diastolic BP among treatment-naive groups. 


\subsubsection{Correlation of eGFR with BMI and CD4+ Cells among Treatment-Naive Groups}

There was a positive and significant correlation of glomerular filtration rate with BMI $(r=0.57, p=0.001)$. There was also a positive but non-significant correlation of glomerular filtration rate with $\mathrm{CD} 4+(\mathrm{r}=0.06, \mathrm{p}=$ $0.63)$ as shown in Table 4.

\subsection{Comparison of Proportion in Creatinine Clearance of Control Groups with HIV Patients}

There are no individuals in HIV+ on HAART with Creatinine clearance $\leq 60 \mathrm{ml} / \mathrm{min}$. The percentages of individuals with Creatinine clearance in between $60 \& 90$ are greater in HIV+ on HAART [14(23.3\%)] than that of HIV+ not on HAART [11(18.3\%)] as shown in Table 5. There are almost similar proportion of individuals with Creatinine clearance above $90 \mathrm{ml} / \mathrm{min}$ in controls [45(75\%)] than that of HIV+ on pre HAART [45(75\%)] and HIV+ on HAART [46(76.7\%)].

\section{Discussion}

Renal disease has been recognized as a common and intimately associated complication of human immunodeficiency virus infection. It is now known that there are several renal syndromes and diseases associated with HIV infection [42]. Although, the incidence of complications is decreasing, HIV infection remains an important risk factor for the development of end stage renal disease [43]. In the US, African Americans have approximately 3 4-fold higher rates of ESRD compared to European Americans [44]. The prevalence of HIVAN among African Americans was estimated at between $3.5 \%$ and $10 \%$ in a primary care setting [11] [45], and at $12 \%$ in an autopsy based study from patients treated with HAART [46]. All of these estimates are significantly higher than the previously maximal conservative estimate of $0.15 \%$ HIVAN cases among Israeli HIV patients of Ethiopian ancestry, and indicates a lack of the factors underlying HIVAN risk in African Americans, and among Israeli Ethiopians HIV carriers [47]. Acute renal injury, identification of patients at high risk, and monitoring renal function after initiation of HAART has been reported from many hospitals in Ethiopia [48] [49].

The present study was conducted to assess renal function abnormalities in HIV infected patients on combination antiretroviral therapy as compared to treatment-naive and HIV-negative control groups at Tikur Anbessa Hospital, Addis Ababa, Ethiopia. The results show significantly $(\mathrm{p}<0.05)$ lower serum total protein in both HIV patients on HAART and HIV+ treatment-naive as compared with the controls. There was significant decrease in total protein by $23.54 \%$ in patients on HAART and by $37.03 \%$ in treatment-naive as compared to control groups. Significantly lower serum total protein in HIV-positive subjects in the present study corroborates earlier studies [14], but contrasts the higher levels in Nigeria reported by Audu et al. (2004) [50]. Decrease in serum total protein in HIV infection has been associated with either increased losses and/or catabolism or as a result of reduction in intake and/or absorption due to sores in the mouth, pharynx and/or oesophagus, fatigue, depression and side effects of medications [51].

The serum urea level of both treatment-naive patients and patients on HAART were not significantly different

Table 4. Correlation of eGFR with BMI and CD4+ cells among treatment-naive groups.

\begin{tabular}{cccc}
\hline & & BMI & CD4+ \\
\hline GFR & $\mathrm{r}$ & 0.57 & 0.06 \\
& $\mathrm{p}$-value & $0.001^{*}$ & 0.63 \\
\hline
\end{tabular}

r-Correlation coefficient; "Indicates significance.

Table 5. Comparison of proportion in Creatinine clearance of controls with HIV patients (percentage in parenthesis).

\begin{tabular}{ccccc}
\hline Variable & Cut off & controls & HIV+ treatment-naive & HIV+ on HAART \\
\hline & $\leq 60$ & $2(3.33)$ & $4(6.7)$ & 0 \\
$\mathrm{CrCl}(\mathrm{ml} / \mathrm{min})$ & $60.01-90$ & $13(21.67)$ & $11(18.3)$ & $14(23.3)$ \\
& $\geq 90.01$ & $45(75)$ & $45(75)$ & $46(76.7)$ \\
\hline
\end{tabular}


as compared with the control group. HIV+ patients on HAART were not also different from HIV+ treatmentnaive patients even though there was an increase in the urea level of HIV+ treatment-naive patients as compared with the control groups. Serum urea concentration is important parameter to determine if the kidneys are functioning properly. A high level of serum urea means the kidneys are not filtering properly. The elevated urea concentration on treatment-naive may suggest pre-renal uremia. It could be as a result of high protein intake or hyper catabolic states including muscle wasting in these patients. Participants on HAART with a low serum urea level can indicate liver dysfunction. Though, urea can at best be a rough guide to renal function, it will ordinarily not be significantly raised until GFR is decreased by at least $50 \%$. The level of serum urea is affected by other factors as nutrition, the degree of dehydration and protein metabolism.

Serum creatinine level shows non-significant increase on treatment-naives by $7.24 \%$ and by $1.43 \%$ on patients on HAART. The high serum creatinine with normal urea concentration in treatment-naives obtained in this study is similar with results obtained in Nigeria [52], in which elevated serum creatinine concentration in $38 \%$ of HIV patients, found in Nigeria. These results differ from previous studies, which found high urea concentration with normal serum creatinine concentration [53]. Serum creatinine is inversely proportional to creatinine clearance, though in this study there were no participants who had serum creatinine values greater than $15 \mathrm{mg} / \mathrm{L}$. This result was in contrast with the findings reported by Andia et al. (2005) [54], in which only 3 patients in the study population had a serum creatinine value $>20 \mathrm{mg} / \mathrm{dL}$. This also could be further explained by the fact that serum creatinine values become, indicative of renal disease only after approximately $50 \%$ of the kidneys have been damaged. In 1998, Wali et al. [55] reported a 37-year old HIV-1 positive African American man with HIVAN requiring hemodialysis. A few months after the beginning of HAART, dialysis was stopped, creatinine and proteinuria improved, and histologic lesions recovered. A similar benefit of HAART is reported by Kirchner (2002) [56], in two African American patients with suspected HIVAN and in one patient with biopsy-proven HIVAN who exhibited marked improvement in renal function after treatment with two nucleoside RTIs and one anti-protease.

The present study also shows significantly $(\mathrm{p}<0.05)$ increased in serum uric acid in treatment-naive by $38.27 \%$ and non-significantly increased by $9.11 \%$ on participants on HAART. Positive effects of HAART on kidney function have been demonstrated in patients infected with HIV. HAART has had little influence on the incidence of end stage renal disease. Lucas et al. (2008) [15] correlated the introduction of HAART with a declining incidence of chronic kidney disease in a cohort of 4509 individuals with HIV [15].

The glomerular filtration rate of treatment-naive participants shows increment by $6.09 \%$ and decrement by $1.13 \%$ in participants on HAART. In an observational, prospective, multicenter cohort study of 1776 outpatients with HIV, viral suppression was associated with improvements in glomerular filtration rate regardless of ethnicity, CD4+ t-cell counts and of baseline renal function. These observations support the hypothesis that HIV-1 replication independently contributes to CKD in advanced stages of the disease. However, GFR improvement independent of viral suppression in individuals with high CD4+ t-cell counts has also been observed [15].

This study shows non-significant decrease in creatinine clearance by $3.46 \%$ in treatment-naives and decrease by $0.25 \%$ on patients on HAART. There was a non-significant difference in the $\mathrm{CrCl}$ values of HIV+ treatmentnaive subjects when compared with healthy controls. The higher number of subjects with decreased creatinine clearance as compared to controls in this study could also be attributed to dietary status, weight loss as a result of the disease. Creatinine clearance can be modified by intake of meat and protein, muscle mass and medications. These modifying factors for GFR and creatinine clearance are especially pertinent in HIV infected patients living in Sub-Saharan Africa [57]. There was no significant difference in the creatinine clearance values of HIV patients who were on ART when compared with those control groups. Schwartz et al. (2005) [58], showed that HAART most likely reduced the AIDS growth rate as well as the progression to HIV-positive ESRD and the mortality rate of HIV positive ESRD patients. Other studies [59] [60], suggested that HAART is associated with decreased prevalence of renal disease and amelioration of progression in the general population and in HIV- infected patients with chronic renal disease. This result however is not in accordance with the findings of Kanai and Hanabusa (2005) [61] of Japan, who reported cases of kidney disease after the introduction of Tenofovir containing HAART. Other drugs (Indinavir, Efavirenz and Keletra) have also been incriminated as the cause of kidney disease in HIV-positive individuals. Tenofovir has been associated with development of ARF and dysfunction of proximal and distal tubules. Indinavir is highly soluble in acidic urine but relatively insoluble in more alkaline urine, predisposing to the development of crystals at typical urine $\mathrm{pH}$ levels.

The prevalence of renal impairment as defined by an $\mathrm{CrCl}<60 \mathrm{ml} / \mathrm{min}$ among $\mathrm{HIV}+$ treatment-naive in this 
study was $6.7 \%$ which is less than previous studies that reported a prevalence rate of $10 \%$ to $30 \%$ [62]-[64]. This value is lower than the one obtained by Wools-Kaloustian et al., (2007) [37] studied a Kenyan cohort of stable HIV infected outpatients. They found out that $11.5 \%$ had a $\mathrm{CrCl}$ less than $60 \mathrm{~mL} / \mathrm{min}$ and $4.8 \%$ less than 50 $\mathrm{mL} / \mathrm{min}$. It was also lower than prevalence rate of 53.3\% reported in South Kenya [65], 23.8\% determined in north central region [66], but higher than 3\% reported in California [67] and 3.5\% in a predominantly Caucasian Euro SIDA cohort in United kingdom [68] [69]. Discordance may be explained by differences in the experimental design, variations in patient population characteristics including demographic characteristics, stage of HIV infection, and access to health care services. However, in a Northern Ugandan study at Gulu Regional Referral Hospital, it was observed to be higher at 36.9\% (eGFR $<90 \mathrm{ml} / \mathrm{min}$ ) renal impairment cases [70], and also in Zambia, very high rate of 33.5\% [71], and in Nigeria 38\% cases were reported [72]. The differences could be due to different eGFR rate used in the experimental protocols of various laboratories.

The mean CD4+ count was significantly higher in controls than HIV infected patients on both pre HAART and HAART. This is consistent with earlier studies that reported an association between impaired renal function in HIV infected patients with significant immunosuppression, having CD4+ T-cell count $<200 \mathrm{cell} / \mu \mathrm{L}$. Immunological AIDS (CD4+ count $<200$ cell $/ \mu \mathrm{L}$ ) is known to be associated with development of opportunistic infections, malignancies and other organ diseases that affects kidney functions [63] [73]-[75]. CD4+ T-cell had a protective role in the development of renal diseases except acute tubular ischaemia [76].

There was a positive and significant correlation of body mass index with systolic blood pressure, diastolic blood pressure. But there was a positive and non- significant correlation of body mass index with age and CD4+ T-cells in treatment-naive participants. This result is in conformity with Mungreiphy et al., (2011) [77], in which age was positively correlated with BMI and both systolic and diastolic BP.

We are aware that some limitations are present in this study. Since both creatinine clearance, serum urea and protein were measured at the same point in time, some short term renal impairement might have been included in the data. Moreover, microalbuminuria was not measured, as it has been shown to be an important marker in identification of renal diseases in HIV-positive groups [27]. Influence of other medications and diet were also not taken into consideration during this retrospective cross sectional-study. However, more powerful studies are needed by using a larger exploratory cohort groups, covering various centres in Ethiopia in order to predict risk of renal diseases in this population.

\section{Conclusion}

There were no statistically significant differences in the levels of creatinine clearance and eGFR in HIV-positive patients (naive as well as treated) as compared to the negative controls. The prevalence of renal impairment as defined by $\mathrm{CrCl}<60 \mathrm{ml} / \mathrm{min}$ is higher in HIV-naive patients than those of patients on HAART and HIV-negative control groups indicating that our data is clinically significant. There was a positive and significant correlation of body mass index with systolic and diastolic blood pressure. It is recommended that periodical monitoring of renal impairment in HIV patients before and after the start of HAART is to be performed for routine care of patients in resource poor settings. If this has to become a routine clinical practice, our results suggest that lack of virologic suppression in HIV-infected ART-naive persons, and maintenance of high CD4+ T-cell counts are modifiable factors that can reduce the risk of renal diseases. It is hoped that this can reduce non-AIDS-defining comorbidity among HIV-infected persons.

\section{Acknowledgements}

This study was funded by Addis Ababa University, Ethiopia. The authors would like to thank the staff at ART clinic of Tikur Anbessa Specialized Hospital, Addis Ababa, Ethiopia, for their technical support and to the study participants, for their cooperation during this study. Financial support to Kassahun Eneyew by Hawasa University, Ethiopia is also gratefully acknowledged.

\section{References}

[1] Armstrong, S., Squarey, S. and Fontaine, C. (2004) UNAIDS 2004 Report on Global AIDS Epidemic. Joint United Nations Programme on HIV/AIDS (UNAIDS), Geneva.

[2] UNAIDS (2012) Report on the Global AIDS Epidemic. Geneva. 
[3] WHO Report on AIDS 2005 UNAIDS and WHO (2005) Joint United Nations Programme on HIV/AIDS.

[4] UNAIDS (2011) World AIDS Day Report 2011. Geneva.

[5] USAID/Ethiopia (2015) HIV/AIDS Health Profile of Ethiopia http://www.ethiopiaatransition.usaid.gov/president\%E2\%80\%99s-emergency-5programaids-relief-pepfar

[6] USAID (2014) Healthy Policy Initiative Equity and Access to ART in Ethiopia. The Joint United Nations Programme on HIV/AIDS. http://www.unaids.org/en/HIV/Data/

[7] Winston, J., Deray, G., Hawkins, T., Szczech, L., Wyatt, C. and Young, B. (2008) Kidney Disease in Patients with HIV Infection and AIDS. Clinical Infectious Diseases, 47, 1449-1457. http://dx.doi.org/10.1086/593099

[8] Rao, T. (1998) Acute Renal Failure in Human Immunodeficiency Virus Infection. Seminars in Nephrology, 18, 378395.

[9] Glassock, R., Cohen, A., Danovitch, G. and Parsa, K. (1990) Human Immunodeficiency Virus and the Kidney. Ann Intern med, 112, 35-49. http://dx.doi.org/10.7326/0003-4819-112-1-35

[10] Lu, T. and Ross, M. (2005) HIV-Associated Nephropathy: A Brief Review. Mount Sinai Journal of Medicine, 72, 193-199.

[11] Ahuja, T., Borucki, M., Funtanilla, M., Shahinian, V., Hollander, M. and Rajaraman, S. (1999) Is the Prevalence of HIV-Associated Nephropathy Decreasing? American Journal of Nephrology, 19, 655-659. http://dx.doi.org/10.1159/000013537

[12] Kopp, J., Falloon, J., Filie, A., Abati, A., King, C., Hortin, G., Mican, J., Vaughan, E. and Miller, K. (2002) IndinavirAssociated Interstitial Nephritis and Urothelial Inflammation: Clinical and Cytologic Findings. Clinical Infectious Diseases, 34, 1122-1128. http://dx.doi.org/10.1086/339486

[13] Afhami, S., Rasoulinejad, M., Razeghi, E., Shahriari, S. and Esmailpour, N. (2007) Renal Disorders in HIV-Infected Patients. Archives of Iranian Medicine, 10, 335-338.

[14] Ogundahunsi, O., Akinyele, Oyegunle, V., Ambali, A. and Mbacham, W. (2008) The Prevalence of Renal Disorder in HIV/AIDS Patients on HAART. International Journal of Biomedical and Health Sciences, 4, 1-4.

[15] Lucas, G., Lau, B., Atta, M., Fine, D., Keruly, J. and Moore, R. (2008) Chronic Kidney Disease Incidence, and Progression to End Stage Renal Disease, in HIV-Infected Individuals: A Tale of Two Races. The Journal of Infectious Diseases, 197, 1548-1557. http://dx.doi.org/10.1086/587994

[16] Coresh, J., Astor, B., Greene, T., Eknoyan, G. and Levey, A. (2003) Prevalence of Chronic Kidney Disease and Decreased Kidney Function in the Adult Us Population: Third National Health and Nutrition Examination Survey. American Journal of Kidney Diseases, 41, 1-12. http://dx.doi.org/10.1053/ajkd.2003.50007

[17] Lucas, G., Eustace, J., Sozio, S., Mentari, E., Appiah, K. and Moore, R. (2004) Highly Active Antiretroviral Therapy and the Incidence of HIV-1-Associated Nephropathy: A 12-Year Cohort Study. AIDS, 18, 541-546. http://dx.doi.org/10.1097/00002030-200402200-00022

[18] Gazzaruso, C., Bruno, .R, Garzaniti, A., Giordanetti, S., Fratino, P., Sacchi, P. and Filice, G. (2003) Hypertension among HIV Patients: Prevalence and Relationships to Insulin Resistance and Metabolic Syndrome. Journal of Hypertension, 21, 1377-1382. http://dx.doi.org/10.1097/00004872-200307000-00028

[19] Brown, T., Li, X., Cole, S., Kingsley, L., Palella, F., Riddler, S., Chmiel, J., Visscher, B., Margolick, J. and Dobs, A (2005) Cumulative Exposure to Nucleoside Analogue Reverse Transcriptase Inhibitors Is Associated with Insulin Resistance Markers in the Multicenter AIDS Cohort Study. AIDS, 19, 1375-1383. http://dx.doi.org/10.1097/01.aids.0000181011.62385.91

[20] Coresh, J., Byrd-Holt, D., Astor, B., Briggs, J., Eggers, P., Lacher, D. and Hostetter, T. (2005) Chronic Kidney Disease Awareness, Prevalence, and Trends among US Adults, 1999 to 2000. Journal of the American Society of Nephrology, 16, 180-188. http://dx.doi.org/10.1681/ASN.2004070539

[21] Shamu, T., Wellington, M., Pascoe, M., Gwanzura, L. and Ndhlovu, C.E. (2015) Incidence of Nephropathy in HIV Infected Patients Receiving Highly Active Antiretroviral Therapy at Newlands Clinic: A Retrospective Study. World Journal of AIDS, 5, 113-123. http://dx.doi.org/10.4236/wja.2015.52014

[22] Belay, E., Seifu, D., Amogne, W. and Kibret, K.T. (2014) Lipid Profile Derangements among Human Immunodeficiency Virus Infected Adults Receiving First Line Anti-Retroviral Therapy in Tikur Anbesa Specialized Hospital, Addis Ababa, Ethiopia: Comparative Cross-Sectional Study. Journal of AIDS \& Clinical Research, 5, 328.

[23] Roling, J., Schmid, H., Fischereder, M., Draenert, R. and Goebel, F. (2006) HIV-Associated Renal Diseases and Highly Active Antiretroviral Therapy-Induced Nephropathy. Clinical Infectious Diseases, 42, 1488-1495. http://dx.doi.org/10.1086/503566

[24] Verhelst, D., Monge, M., Meynard, J., Fouqueray, B., Mougenot, B., Girard, P., Ronco, P. and Rossert, J. (2002) Fanconi Syndrome and Renal Failure Induced By Tenofovir: A First Case Report. American Journal of Kidney Diseases, 
40, 1331-1333. http://dx.doi.org/10.1053/ajkd.2002.36924

[25] Izzedine, H., Launay-Vacher, V. and Deray, G. (2005) Antiviral Drug Induced Nephrotoxicity. American Journal of Kidney Diseases, 45, 804-817. http://dx.doi.org/10.1053/j.ajkd.2005.02.010

[26] McComsey, G.A., Kitch, D., Daar, E.S., Tierney, C., Jahed, N.C., Melbourne, K., Ha, B., Brown, T.T., Bloom, A., Fedarko, N. and Sax, P.E. (2012) Inflammation Markers after Randomization to Abacavir/Lamivudine or Tenofovir/Emtricitabine with Efavirenz or Atazanavir/Ritonavir. AIDS, 26, 1371-1385. http://dx.doi.org/10.1097/QAD.0b013e328354f4fb

[27] Chaves, H.L., Batista, M.P., Gomes, A.M., Costa, A.A., Lima, A.T., Ceara, V.D.A., Caravalho, P.R.A., Sampio, L.A., Bezerra, F.M. and Medeiros, M.S. (2014) Microalbuminuria and Kidney Disease Risk in HIV-Patients Taking Combined Antiretroviral Therapy. World Journal of AIDS, 2014, 4, 242-248. http://dx.doi.org/10.4236/wja.2014.42029

[28] Berns, J., Cohen, R., Silverman, M. and Turner, J. (1997) Acute Renal Failure Due to Indinavir Crystalluria and Nephrolithiasis: Report of Two Cases. American Journal of Kidney Diseases, 30, 558-560. http://dx.doi.org/10.1016/S0272-6386(97)90316-4

[29] Kopp, J., Miller, K., Mican, J., Feuerstein, I., Vaughan, E., Baker, C., Pannell, L.K. and Falloon, J. (1997) Crystalluria and Urinary Tract Abnormalities Associated with Indinavir. Annals of Internal Medicine, 127, 119-125. http://dx.doi.org/10.7326/0003-4819-127-2-199707150-00004

[30] Gagnon, R., Tecimer, S., Watters, A. and Tsoukas, C. (2000) Prospective Study of Urinalysis Abnormalities in HIV-Positive Individuals Treated with Indinavir. American Journal of Kidney Diseases, 36, 507-515. http://dx.doi.org/10.1053/ajkd.2000.9791

[31] Lin, J., Chen, I., Vastag, K. and Ostovic, D. (1995) pH-Dependent Oral Absorption of L-735,524, a Potent HIV Protease Inhibitor, in Rats and Dogs. Drug Metabolism and Disposition, 23, 730-735.

[32] Hortin, G., King, C., Miller, K. and Kopp, J. (2000) Detection of Indinavir Crystals in Urine: Dependence on Method of Analysis. Archives of Pathology \& Laboratory Medicine, 124, 246-250.

[33] Daudon, M., Estepa, L., Viard, J.P., Joly, D., Jungers, P. (1997) Urinary Stones in HIV-1-Positive Patients Treated with Indinavir. Lancet, 349, 1294-1295. http://dx.doi.org/10.1016/S0140-6736(05)62506-8

[34] Winston, J., Deray, G., Hawkins, T., Szczech, L., Wyatt, C. and Young, B. (2008) Kidney Disease in Patients with HIV Infection and AIDS. Clinical Infectious Diseases, 47, 1449-1457. http://dx.doi.org/10.1086/593099

[35] Carbone, L., D’Agati, V., Cheng, J. and Appel, G. (1989) Course and Prognosis of Human Immunodeficiency Virus-Associated Nephropathy. American Journal of Medicine, 87, 389-395. http://dx.doi.org/10.1016/S0002-9343(89)80819-8

[36] Gupta, S., Eustace, J. and Winston, J. (2005) Guidelines for the Management of Chronic Kidney Disease in HIV-Infected Patients: Recommendations of the HIV Medicine Association of the Infectious Diseases Society of America. Clinical Infectious Diseases, 40, 1559-1585. http://dx.doi.org/10.1086/430257

[37] Wools-Kaloustian, K., Gupta, S.K., Muloma, E., Owino-Ong’or, W., Sidle, J., Aubrey, R.W., Shen, J., Kipruto, K., Zwickl, B.E. and Goldman, M. (2007) Renal Disease in An Antiretroviral-Naive HIV-Infected Outpatient Population in Western Kenya. Nephrology Dialysis Transplantation, 22, 2208-2212. http://dx.doi.org/10.1093/ndt/gfm223

[38] Bartels, H. and Böhmer, M. (1971) Micro-Determination of Creatinine. Clinica Chimica Acta, 32, 81-85.

[39] Levey, A., Coresh, J., Greene, T., Stevens, L., Zhang, Y., Hendriksen, S., Kusek, J. and van Lente, F. (2006) Chronic Kidney Disease Epidemiology Collaboration. Using Standardized Serum Creatinine Values in the Modification of Diet in Renal Disease Study Equation for Estimating Glomerular Filtration Rate. Annals of Internal Medicine, 145, 247-254. http://dx.doi.org/10.7326/0003-4819-145-4-200608150-00004

[40] Fossati, P., Prencipe, L. and Berti, G. (1980) Use of 3,5-Dichloro-2 Hydroxy-Benzenesulfonic Acid/4-Aminophenazone Chromogenic System in Direct Enzymic Assay of Uric Acid in Serum and Urine. Clinical Chemistry, 26, 227231.

[41] Cockcroft, D. and Gault, M. (1976) Prediction of Creatinine Clearance from Serum Creatinine. Nephron, 16, 31-41. http://dx.doi.org/10.1159/000180580

[42] Cohen, S., Cukor, D., Peterson, R. and Kimmel, P. (2007) Psychosocial Aspects of Chronic Disease: ESRD as a Paradigmatic Illness. Journal of the American Society of Nephrology, 18, 3042-3055. http://dx.doi.org/10.1681/ASN.2007030345

[43] Eggers, P. and Kimmel, P. (2004) Is There an Epidemic of HIV Infection in the US ESRD Program? Journal of the American Society of Nephrology, 15, 2477-2485. http://dx.doi.org/10.1097/01.ASN.0000138546.53152.A7

[44] Coresh, J., Hallan, S., Astor, B., Romundstad, S., Aasarød, K., Kvenild, K. and Coresh, J. (2007) Association of Kidney Function and Albuminuria with Cardiovascular Mortality in Older vs Younger Individuals: The HUNT II Study. Archives of Internal Medicine, 167, 2490-2496. http://dx.doi.org/10.1001/archinte.167.22.2490 
[45] D’agati, V., Suh, J., Carbone, L., Cheng, J. and Appel, G. (1989) Pathology of HIV-Associated Nephropathy: A Detailed Morphologic and Comparative Study. Kidney International, 35, 1358-1370. http://dx.doi.org/10.1038/ki.1989.135

[46] Shaninian, V. (2000) Prevalence of HIV-Associated Nephropathy in Autopsies of HIV-Infected Patients. American Journal of Kidney Diseases, 35, 884-888. http://dx.doi.org/10.1016/S0272-6386(00)70259-9

[47] Behar, D., Shlush, L., Maor, C., Lorber, M. and Skorecki, K. (2006) Absence of HIV Associated Nephropathy in Ethiopians. American Journal of Kidney Diseases, 47, 88-94. http://dx.doi.org/10.1053/j.ajkd.2005.09.023

[48] Phillips, L., Allen, N., Phillips, B., Abera, A., Diro, E., Riley, S., Tadesse, Y., Williams, J. and Phillips, A. (2013) Acute Kidney Injury Risk Factor Recognition in Three Teaching Hospitals in Ethiopia. South African Medical Journal, 103, 413-418. http://dx.doi.org/10.7196/samj.6424

[49] Girma, J., Umeta, M. and Tsegaye, A. (2015) Effect of $1^{\text {st }}$ Line Highly Active Anti-Retroviral Therapy (HAART) on the Development of Renal Failure in Human Immunodeficiency Virus (HIV)-Infected Patients Attending ART Clinic of St. Paul's General Specialized Hospital, Addis Ababa: A Retrospective Cross Sectional Study. CIBTech Journal of Pharmaceutical Sciences, 4, 32-42. http://www.cibtech.org/cjps.htm

[50] Audu, I., Agwale, S., Tanimoto, L., Womack, C., Odama, L., Leung, K., Duey, D., Negedu-Momoh, R., Mohammed, S., Inyang, U., Graham, B. and Ziermann, R. (2004) Prevalence of HCV Coinfection in HIV-Infected Individuals in Nigeria and Characterization of HCV Genotypes. Journal of Clinical Virology, 31, S3-S6. http://dx.doi.org/10.1016/j.jcv.2004.09.001

[51] Macallan, D.C. (1999) Nutrition and Immune Function in Human Immunodeficiency Virus Infection. Proceedings of the Nutrition Society, 58, 743-748. http://dx.doi.org/10.1017/S002966519900097X

[52] Emem, C., Arogundade, F., Sanusi, A., Adelusola, K., Wokoma, F. and Akinsola, A. (2008) Renal Disease in HIV-Seropositive Patients in Nigeria: An Assessment of Prevalence, Clinical Features and Risk Factors. Nephrology Dialysis Transplantation, 23, 741-746. http://dx.doi.org/10.1093/ndt/gfm836

[53] Emejulu, A., Onwuliri, V. and Ojiako, O. (2011) Electrolyte Abnormalities and Renal Impairment in Asymptomatic HIV-infected Patients in Owerri, South Eastern Nigeria. Australian Journal of Basic and Applied Sciences, 5, 257-260.

[54] Andia, I., Pepper, L. and Matthieson, P. (2005) Prevalence of Renal Disease in Outpatients with HIV/AIDS in Mbarara Hospital. The 3rd International AIDS Society Conference on HIV Pathogenesis and Treatment, Rio de Janeiro, 24-27 July 2005.

[55] Wali, R., Drachenberg, C., Papadimitriou, J., Keay, S. and Ramos, E. (1998) HIV-1-Associated Nephropathy and Response to Highly-Active Antiretroviral Therapy. Lancet, 352, 783-784. http://dx.doi.org/10.1016/S0140-6736(98)24037-2

[56] Kirchner, J. (2002) Resolution of Renal Failure after Initiation of HAART: 3 Cases and a Discussion of the Literature. AIDS Reader, 12, 103-105, 110-112.

[57] Schwartz, G. and Furth, S. (2007) Glomerular Filtration Rate Measurement and Estimation in Chronic Kidney Disease. Pediatric Nephrology, 22, 1839-1848. http://dx.doi.org/10.1007/s00467-006-0358-1

[58] Schwartz, E.J., Szczech, L.A., Ross, M.J., Klotman, M.E., Winston, J.A. and Klotman, P.E. (2005) Highly Active Antiretroviral Therapy and the Epidemic of HIV+ End-Stage Renal Disease. Journal of the American Society of Nephrology, 16, 2412-2420. http://dx.doi.org/10.1681/ASN.2005040340

[59] Szczech, L., Edwards, L., Sanders, L., van der Horst, C., Bartlett, J., Heald, A. and Svetkey, L. (2002) Protease Inhibitors Are Associated with a Slowed Progression of HIV-Related Renal Diseases. Clinical Nephrology, 57, 336-341. http://dx.doi.org/10.5414/CNP57336

[60] Kimmel, P. (2003) Pathogenesis and Treatment of HIV-Associated Renal Disease: Lessons from Clinical and Animal Studies, Molecular Pathologic Correlations, and Genetic Investigations. Annals of Internal Medicine, 139, 214-226. http://dx.doi.org/10.7326/0003-4819-139-3-200308050-00019

[61] Kanai, E. and Hanabusa, H. (2005) Renal Tubular Toxicity Associated with Tenofovir Assessed Using Urine-Beta 2 Micro Globulin Alkaline Phosphatase Levels. AIDS, 19, 2031-2033. http://dx.doi.org/10.1097/01.aids.0000194130.05264.83

[62] Weiner, N., Goodman, J. and Kimmel, P. (2002) The HIV Associated Renal Diseases, Current Insight into Pathogenesis and Treatment. Kidney International, 63, 1618-1631. http://dx.doi.org/10.1046/j.1523-1755.2003.00901.x

[63] Szczech, L., Hoover, D., Feldman, J., Cohen, M., Gange, S. and Gooze, L. (2004) Association between Renal Disease and Outcomes among HIV-infected Women Receiving or Not Receiving Antiretroviral Therapy. Clinical Infectious Diseases, 39, 1199-1206. http://dx.doi.org/10.1086/424013

[64] Winston, A., Lehane, D., Gray, R. and Daskal, Y. (1979) The Effect of Diuretic Pre-Treatment on Clinical, Morphological and Ultrastructural Cis-Platinum Induced Nephrotoxicity. International Journal of Radiation Oncology, Biology, Physics, 5, 1393-1399. http://dx.doi.org/10.1016/0360-3016(79)90677-1 
[65] Okafor, U.H., Unuigbe, E.I. and Wokoma, F.S. (2011) Spectrum of Clinical Presentations in Human Immunodeficiency Virus (HIV) Infected Patients with Renal Disease. African Journal of Infectious Diseases, 5, 28-32. http://dx.doi.org/10.4314/ajid.v5i2.66509

[66] Agbaji, O., Onu, A., Agaba, P., Muazu, M., Falang, K. and Idoko, J. (2011) Predictors of Impaired Renal Function among HIV Infected Patients Commencing Highly Active Antiretroviral Therapy in Jos, Nigeria. Nigerian Medical Journal, 52, 182-185. http://dx.doi.org/10.4103/0300-1652.86133

[67] Crum-Cianflone, N., Ganesan, A., Teneza-Mora, N., Riddle, M., Barahona, M.S. and Brodine, S. (2010) Prevalence and Factors Associated with Renal Dysfunction among HIV-Infected Patients. AIDS Patient Care and STDs, 24, 353-360. http://dx.doi.org/10.1089/apc.2009.0326

[68] Mocroft, A., Kirk, O., Gatell, J., Reiss, P., Gargalianos, P., Zilmer, K., Beniowski, M., Viard, J.-P., Staszewski, S. and Lundgren, J.D. (2007) Chronic Renal Failure among HIV-1-Infected Patients. AIDS, 21, 1119-1127. http://dx.doi.org/10.1097/QAD.0b013e3280f774ee

[69] Mocroft, A., Kirk, O., Reiss, P., De Wit, S., Sedlacek, D., Beniowski, M., Gatell, J., Phillips, A.N., Ledergerber, B. and Lundgren, J.D. (2010) Estimated Glomerular Filtration Rate, Chronic Kidney Disease and Antiretroviral Drug Use in HIV-Positive Patients. AIDS, 24, 1667-1678. http://dx.doi.org/10.1097/QAD.0b013e328339fe53

[70] Odongo, P., Wanyama, R., Obol, J.H., Apiyo, P. and Byakika-Kibwika, P. (2015) Impaired Renal Function and Associated Risk Factors in Newly Diagnosed HIV-Infected Adults in Gulu Hospital, Northern Uganda. BMC Nephrology, 16, 43. http://dx.doi.org/10.1186/s12882-015-0035-3

[71] Mulenga, L.B., Kruse, G., Lakhi, S., Cantrell, R.A., Reid, S.E., Zulu, I., Stringer, E.M., Krishnasami, Z., Mwinga, A., Saag, M.S., et al. (2008) Baseline Renal Insufficiency and Risk of death among HIV-Infected Adults on Antiretroviral Therapy in Lusaka, Zambia. AIDS, 22, 1821-1827. http://dx.doi.org/10.1097/QAD.0b013e328307a051

[72] Onodugo, O.D., Chukwuka, C., Onyedum, C., Ejim, E., Mbah, A., Nkwo, P., Ugwu, G., Ukoma, U., Okafor, C., Anyene, C. and Nwabueze, E. (2014) Baseline Renal Function among Antiretroviral Therapy-Naive, HIV-Infected Patients in Southeast Nigeria. Journal of the International Association of Providers of AIDS Care (JIAPAC), 13, 476-480. http://dx.doi.org/10.1177/2325957413488169

[73] Winston, J., Klotman, M. and Klotman, P. (1999) HIV Associated Nephropathy Is a Late, Not Early, Manifestation of HIV-1 Infection. Kidney International, 55, 1036-1040. http://dx.doi.org/10.1046/j.1523-1755.1999.0550031036.x

[74] Winston, J., Bruggeman, L. and Ross, M. (2001) Nephropathy and Establishment of a Renal Reservoir of HIV Type 1 during Primary Infection. The New England Journal of Medicine, 344, 1979-1984. http://dx.doi.org/10.1056/NEJM200106283442604

[75] Krawczyk, C., Holmberg, S., Moorman, A., Gardner, L. and McGwinjnr, G. (2004) Factors Associated with Chronic Renal Failure in HIV Infected Ambulatory Patients. AIDS, 18, 2171-2178. http://dx.doi.org/10.1097/00002030-200411050-00009

[76] Wang, Y., Feng, X. and Bao, S. (2005) Depletion of CD4 ${ }^{+}$T Cells Aggravate Glomerular and Interstitial Injury in Murine Adriamycin Nephropathy. Kidney International, 59, 975-984. http://dx.doi.org/10.1046/j.1523-1755.2001.059003975.x

[77] Mungreiphy, N.K., Kapoor, S. and Sinha, R. (2011) Association between BMI, Blood Pressure, and Age: Study among Tangkhul Naga Tribal Males of Northeast India. Journal of Anthropology, 127, 119-125.

http://dx.doi.org/10.1155/2011/748147 


\section{Abbreviations Used}

ACE-Angiotensin-converting enzyme;

ADH-Antidiuretic hormone;

AIDS-Acquired immunodeficiency syndrome;

ARF-Acute renal failure

ART-Antiretroviral therapy;

BMI-Body mass index;

cART — combination antiretroviral therapy;

CD4-Cluster of differentiation 4;

CKD_Chronic kidney disease;

CrCl-Creatinine clearance;

CRF-Chronic renal failure;

DHBS - Dichloro-2-hydroxybenzene sulfonate;

ECF-Extracellular fluid;

EIA-Enzyme Immunio assay;

eGFR — estimated Glomerular filtration rate;

ESRD_-End stage renal disease;

FSGS-Focal segmental glomerulosclerosis;

GLDH_-Glutamate dehydrogenase;

HAART - Highly active antiretroviral therapy;

HIV_-Human immunodeficiency virus;

HIVAN-HIV-associated nephropathy;

IDSA-Infectious disease society of America;

MDRD-Modified Diet in Renal Disease;

NADH-Nicotinamide adenine dinucleotide;

RTI-Reverse transcriptase inhibitors;

USRDS-United States renal data system;

UNAIDS - United nation program for acquired immunodeficiency Syndrome;

WHO_-World health organization.

\section{Submit or recommend next manuscript to SCIRP and we will provide best service for you:}

Accepting pre-submission inquiries through Email, Facebook, LinkedIn, Twitter, etc.

A wide selection of journals (inclusive of 9 subjects, more than 200 journals)

Providing 24-hour high-quality service

User-friendly online submission system

Fair and swift peer-review system

Efficient typesetting and proofreading procedure

Display of the result of downloads and visits, as well as the number of cited articles

Maximum dissemination of your research work

Submit your manuscript at: http://papersubmission.scirp.org/ 